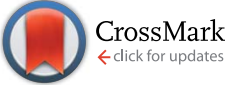

Cite this: RSC Adv., 2017, 7, 14219
Received 28th January 2017 Accepted 24th February 2017

DOI: 10.1039/c7ra01236e

rsc.li/rsc-advances

\section{Field emission properties of Al-doped ZnO nanosheet based on field emitter device with UV exposure}

\author{
Sheng-Joue Young* and Yi-Hsing Liu \\ In this study, aluminum ( $\mathrm{Al}$ )-doped zinc oxide $(\mathrm{ZnO})$ nanosheets were synthesized on a $\mathrm{ZnO} /$ glass substrate \\ under different growth temperatures using a modified aqueous solution method. The field emission and \\ physical properties of Al-doped $\mathrm{ZnO}$ nanosheets were then investigated. Results indicated that high \\ growth temperature improves the quality of Al-doped ZnO nanosheets. Moreover, the \\ photoluminescence intensity of the sample's ultraviolet (UV) emission peak (growth temperature at 60 \\ ${ }^{\circ} \mathrm{C}$ ) was stronger compared with those of other samples. However, its broad, deep-level green emission \\ band was weaker. The turn-on field and field enhancement factor $(\beta)$ of Al-doped ZnO nanosheets were \\ $3.8 \mathrm{~V} \mathrm{\mu m}^{-1}$ and 4760, respectively. The UV illumination of the Al-doped $\mathrm{ZnO}$ nanosheets decreased the \\ turn-on electrical field from 3.8 to $3.3 \mathrm{~V} \mathrm{\mu m}^{-1}$ and elevated the $\beta$ from 4760 to 7501.
}

\section{Introducion}

Field emission-based displays and electronic device applications have been studied for decades and have continued to attract interest because of their potential applications in flat panel displays, vacuum microwave amplifiers, and lamps. These applications are commonly used in everyday living, medicine, and research. ${ }^{1-3}$ The advantages and disadvantages of field emission devices can be attributed to their geometrical structures and material properties. These characteristics include one-dimensional nanostructures, which offer low work function, high mechanical stability, conductivity, and aspect ratios. ${ }^{4,5}$ Recently, one-dimensional nanostructures (nanowires, nanorods, and nanotips) have been developed as electron field emitters because of their negative electron affinity, high mechanical strength, and chemical stability. Zinc oxide (ZnO) nanostructures have been extensively studied because of their remarkable physical and chemical properties that can be exploited in various electronic and optoelectronic devices. $\mathrm{ZnO}$ nanostructures with different geometrical morphologies have been enhanced using diverse synthetic methods, such as chemical vapor deposition, hydrothermal method, pulsed laser deposition, and furnace and electrochemical deposition. ${ }^{6-10}$ The performance of field emission-based devices has been improved by doping with various metal elements, such as aluminum (Al), gallium, and indium. Field emission-based devices with improved performance have potential applications in optoelectronic devices and enhanced optical and electrical properties. ${ }^{11-14}$ It has been reported that field emission properties are

Department of Electronic Engineering, National Formosa University, Yunlin 632, Taiwan. E-mail: shengjoueyoung@gmail.com mainly dependent on the dimension, morphology, and apex geometry of one-dimensional nanostructure. Recently, onedimensional $\mathrm{ZnO}$ nanostructures have been discussed for the field emission device, such as Z. Zhang et al. reported the influence of morphologies and doping of nanostructured $\mathrm{ZnO}$ on the field emission behaviors by using metal-organic chemical vapor deposition $\left(>600{ }^{\circ} \mathrm{C}\right) \cdot{ }^{15} \mathrm{~F}$. Ye et al. reported field emission of Al-doped ZnO films by using DC magnetron sputtering. ${ }^{16} \mathrm{~K}$. Mahmood et al. reported the enhanced and stable field emission behavior of a novel electrosprayed Al-doped $\mathrm{ZnO}$ bilayer film by using electrosprayed method $\left(>160{ }^{\circ} \mathrm{C}\right) \cdot{ }^{17} \mathrm{C}$. L. Hsu et al. reported enhanced field emission of Al-doped $\mathrm{ZnO}$ nanowires grown on a flexible polyimide substrate by using hydrothermal method $\left(>90{ }^{\circ} \mathrm{C}\right) .{ }^{18}$ However, it is very rare that study and low temperature fabrication of two dimensional $\mathrm{Al}-$ doped $\mathrm{ZnO}$ nanostructure. In the study, well-aligned $2 \mathrm{D} \mathrm{Al}-$ doped $\mathrm{ZnO}$ nanosheets were synthesized on a glass substrates by low-temperature $\left(<70^{\circ} \mathrm{C}\right)$ aqueous solution method.

\section{Experimental}

Prior to preparation, the glass substrate was cleaned with a standard cleaning process. Then, the substrates were dried in an oven. Using the two-step deposition process, a $25 \mathrm{~nm}$-thick ZnO seed layer was first deposited onto a glass substrate through RF magnetron sputtering system. The size of the target was a 3-inch $\mathrm{ZnO}(99.99 \%)$. The base pressure was $5 \times 10^{-6}$ torr. Argon and oxygen flow rates were maintained at 18 and $2 \mathrm{sccm}$, respectively. The chamber's working pressure was maintained at $1 \times 10^{-2}$ torr. Radio frequency power was maintained at $100 \mathrm{~W}$ during the $5 \mathrm{~min}$ deposition process. In the second step of deposition, Al-doped $\mathrm{ZnO}$ nanosheets with four different 
parameters were grown using a modified aqueous solution method. This step was performed in a beaker with $0.1 \mathrm{M}$ zinc (Zn) nitrate hexahydrate and $0.4 \mathrm{M}$ sodium hydroxide. The $\mathrm{Al}$ dopant was added as $\mathrm{Al}$ nitrate at $1 \%$ equimolar concentration. The growth solution was constantly stirred for $1 \mathrm{~h}$ at $40{ }^{\circ} \mathrm{C}$, $50{ }^{\circ} \mathrm{C}$, and $60^{\circ} \mathrm{C}$. Finally, the sample was washed with deionized water and dried at room temperature. Before the examination of the field emission characteristics, a 100 nm-thick Ag film was deposited onto the Al-doped $\mathrm{ZnO}$ nanosheets using an electronbeam evaporator. The Ag film acted as the contact electrode.

The surface morphologies of the Al-doped $\mathrm{ZnO}$ nanosheets were observed with a field emission scanning electron microscope (FESEM, Hitachi-S-4800-I). The crystallinity of Al-doped $\mathrm{ZnO}$ nanosheets was analyzed with an X-ray diffractometer (XRD, Bruker D8 advance). The field emission properties of the Al-doped ZnO nanosheets were examined using a Keithley 2410 System in a homemade vacuum chamber. Pressure was maintained at less than $5 \times 10^{-6}$ torr in the chamber. A $5 \mathrm{~mm}(\mathrm{~L}) \times$ $30 \mathrm{~mm}$ (W) indium (In) tin oxide glass functioned as the anode and the $\mathrm{Al}$-doped $\mathrm{ZnO}$ nanosheet served as the cathode. The anode-cathode distance was $140 \mu \mathrm{m}$. To measure emission current, a 0-1100 V was applied into the devices in $10 \mathrm{~V}$ increments by Keithley 2410 System.

\section{Results and discussion}

Fig. 1 shows the typical XRD pattern of Al-doped ZnO nanosheets prepared under different temperatures on a $\mathrm{ZnO} /$ glass substrate. The sharp diffraction peaks from the Al-doped $\mathrm{ZnO}$ nanosheets were attributed to hexagonal wurtzite ZnO (JCPDS card no. 36-1451). The (002) diffraction peak intensity was considerably stronger compared with those of the other peaks. This finding indicated that the Al-doped $\mathrm{ZnO}$ nanosheet crystals preferentially grew along the $c$-axis, which was perpendicular to the substrate surface. Moreover, all samples, which were prepared under different temperatures, displayed a (002) peak with full-width at half-maximum (FWHM) values of 0.2913 (sample 1), 0.27336 (sample 2), and 0.27142 (sample 3). This result suggested that the quality of Al-doped $\mathrm{ZnO}$ nanosheets can be improved by high growth temperatures. In addition, no other diffraction peaks were observed in the samples, which suggested the absence of impurities and the complete transformation of the precursor into the $\mathrm{ZnO}$ phase.

Fig. 2 exhibits the FE-SEM images of Al-doped $\mathrm{ZnO}$ nanosheets prepared on a $\mathrm{ZnO} /$ glass substrate under varying growth temperatures. The images show that high-density nanosheets were successfully grown on the $\mathrm{ZnO} /$ glass substrate. The nanosheets were connected to each other as net-shaped films.

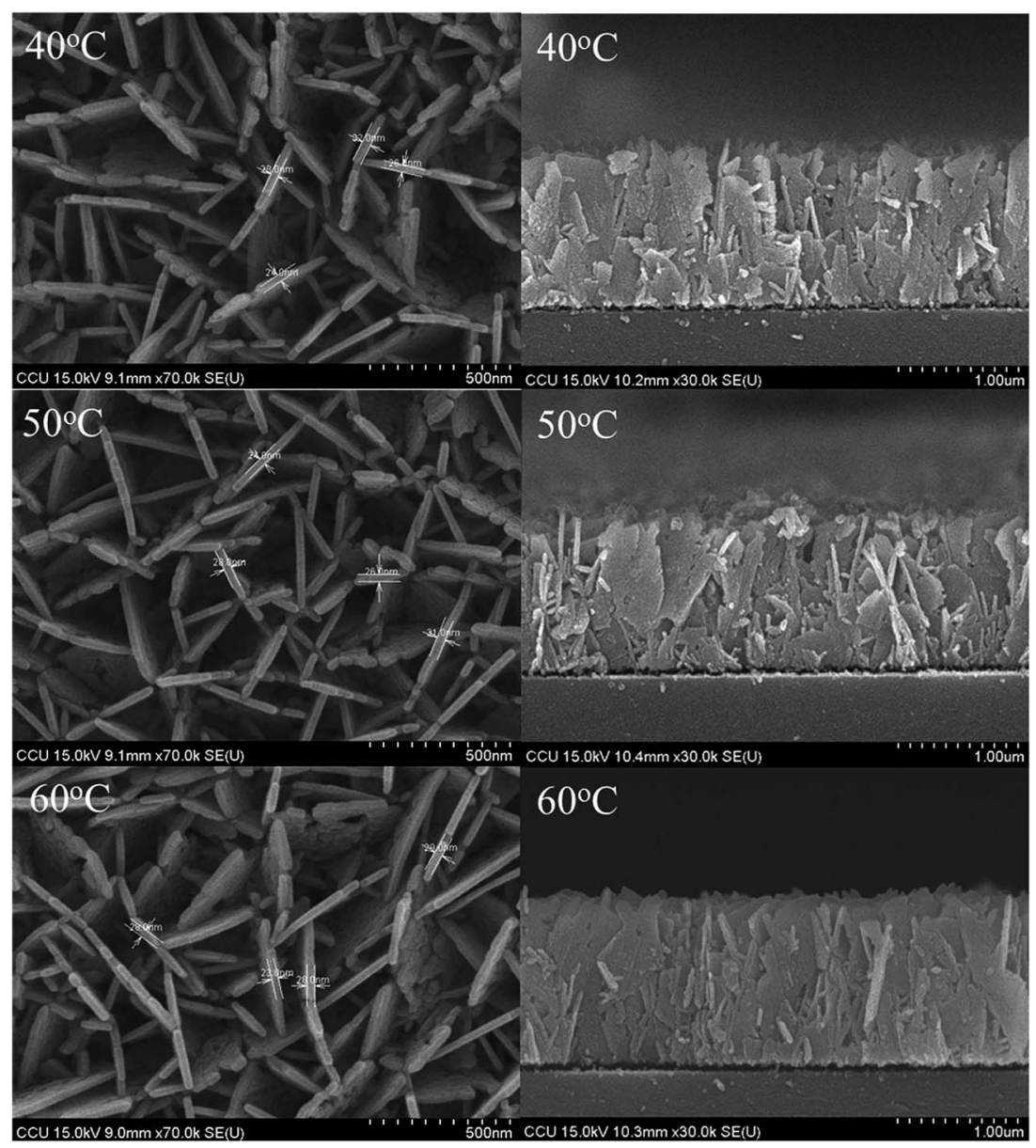

Fig. 1 FESEM images of AZO nanosheets samples, which the growth temperature from $40{ }^{\circ} \mathrm{C}$ to $60^{\circ} \mathrm{C}$. 


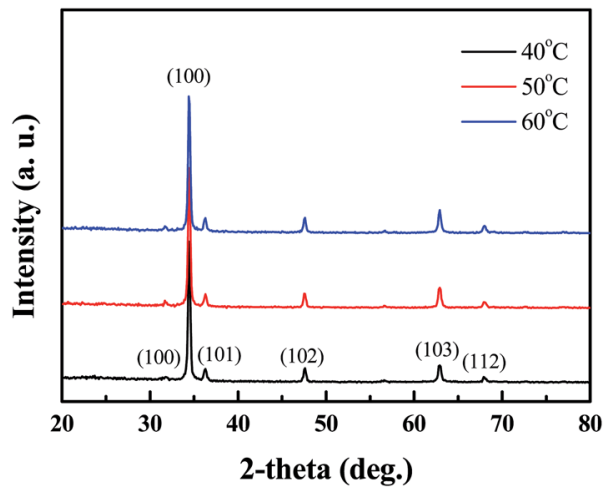

Fig. 2 XRD patterns of AZO nanosheets samples, which the growth temperature from $40{ }^{\circ} \mathrm{C}$ to $60^{\circ} \mathrm{C}$

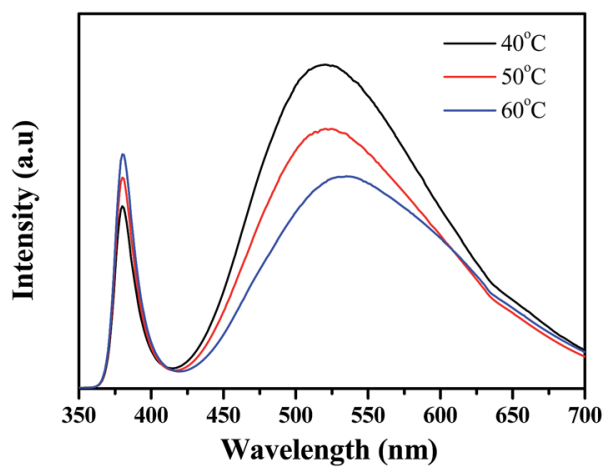

Fig. 3 Presents the room-temperature photoluminescence (PL) spectrum of $\mathrm{Al}$-doped $\mathrm{ZnO}$ nanosheet samples after excitation with a $\mathrm{He}-\mathrm{Cd}$ laser, which the growth temperature from $40^{\circ} \mathrm{C}$ to $60^{\circ} \mathrm{C}$.

Most nanosheets were oriented perpendicular to the substrate surface. This alignment is strongly consistent with the strong (002) diffraction peak intensity observed in the XRD pattern. The thickness and length of the Al-doped $\mathrm{ZnO}$ nanosheets were approximately $23-32 \mathrm{~nm}$ and $1.34 \mu \mathrm{m}, 24-31 \mathrm{~nm}$ and $1.33 \mu \mathrm{m}$, and $23-29 \mathrm{~nm}$ and $1.44 \mu \mathrm{m}$ for samples 1,2 , and 3, respectively. These findings demonstrated that morphology of the sheets did not significantly change in response to growth temperature.

Fig. 3 presents the room-temperature photoluminescence (PL) spectrum of Al-doped $\mathrm{ZnO}$ nanosheet samples after excitation with a He-Cd laser. The typical luminescence behavior of $\mathrm{ZnO}$ nanostructures produced a narrow ultraviolet (UV) emission peak and a broad green emission band. The figure clearly shows a peak at approximately $380 \mathrm{~nm}$ and a broad deep-level emission at 500$600 \mathrm{~nm}$. The sample's UV emission peaks are attributed to the combination of free excitons caused by exciton-exciton collision $(\sim 3.3 \mathrm{eV}) . .^{19}$ Deep-level defects, such as oxygen vacancies, oxygen interstitials, $\mathrm{Zn}$ vacancies, and $\mathrm{Zn}$ interstitials, were found at approximately 2.06 to $2.5 \mathrm{eV}^{20-22}$ The sample displayed stronger UV emission peak intensity (growth temperature at $60^{\circ} \mathrm{C}$ ) than those of other samples. However, its broad, deep-level green emission band was also weaker. The nanostructure's structural quality can be evaluated with the ratio of UV emission intensity to deep-level emission intensity, which is denoted as $Q$ in this paper. The calculated $Q$ values of the samples were 0.5627 (sample 1), 0.812 (sample 2), and 1.103 (sample 3) for Al-doped $\mathrm{ZnO}$ nanosheets at different growth temperatures. This difference likely resulted from interactions between $\mathrm{Al}$ and $\mathrm{Zn}$ ions and increased growth temperatures. These two conditions, which consumed oxygen ions, decreased the concentration of interstitial oxygen in the Al-doped $\mathrm{ZnO}$ nanosheets.

Table 1 presents the results of the physical property analysis. The results revealed that sample 3 had the best physical properties among all samples. Therefore, sample 3 was used in the subsequent experiments. A field emission device was examined in a vacuum chamber that was evacuated to a base pressure of $<5 \times 10^{-6}$ mtorr. The as-prepared nanostructures on the glass substrate $\left(25 \mathrm{~mm}^{2}\right)$ were utilized as a cathode and the indiumdoped tin oxide glass plate served as the anode. The current density curves of the Al-doped $\mathrm{ZnO}$ nanosheet device in the dark and under UV illumination (wavelength $=365 \mathrm{~nm}$ ) are presented in Fig. 4(a). In this figure, the density curves are plotted the as a function of applied field $(J-E)$. To further determine the field emission measurements of the Al-doped $\mathrm{ZnO}$ nanosheets, the measured current density electric field curves were analyzed using the Fowler-Nordheim (F-N) equation: ${ }^{23}$

$$
J=A \times\left(\frac{\beta^{2} \times E^{2}}{\varnothing}\right) \times \exp \left(-\frac{B \times \emptyset^{\frac{3}{2}}}{E \times \beta}\right),
$$

where $J$ is the current density; $E$ is the applied field between the anode and cathode; $A$ and $B$ are the constants $\left(A=1.56 \times 10^{-10} \mathrm{~A}\right.$ $\left.\mathrm{V}^{-2} \mathrm{eV}, B=6.83 \times 10^{9} \mathrm{~V} \mathrm{eV}^{-3 / 2} \mu \mathrm{m}^{-1}\right)$; $\varnothing$ is the work function of the emitting material, which is approximately $5.3 \mathrm{eV}$ for $\mathrm{ZnO} ;{ }^{24}$ and $\beta$ is the effective field enhancement factor. The turn-on field was defined as the electric field that corresponds to a $10^{-6} \mathrm{~A} \mathrm{~cm}^{-2}$ current density. The turn-on electric fields of the device were $3.8 \mathrm{~V} \mathrm{\mu m}^{-2}$ in the dark and $3.3 \mathrm{~V} \mathrm{\mu m}^{-2}$ under UV illumination (see Table 2). We further simplified the F-N equation to thoroughly investigate the effect of field enhancement factor: ${ }^{25}$

$$
\ln \left(\frac{J}{E^{2}}\right)=\ln \left(\frac{A \times \beta^{2}}{\varnothing}\right)-\left(\frac{B \times \emptyset^{\frac{3}{2}}}{E \times \beta}\right)
$$

Table 1 Presents the results of the physical property analysis

\begin{tabular}{lllll}
\hline Growth temperature & Length $(\mu \mathrm{m})$ & Thickness $(\mathrm{nm})$ & XRD (002) peak to FWHM value \\
\hline $40{ }^{\circ} \mathrm{C}$ (sample 1) & 1.34 & $24-32$ & 0.2913 & 0.5627 \\
$50{ }^{\circ} \mathrm{C}$ (sample 2) & 1.33 & $24-31$ & 0.27336 & 0.812 \\
$60^{\circ} \mathrm{C}$ (sample 3) & 1.44 & $23-29$ & 0.27142 & 1.103
\end{tabular}




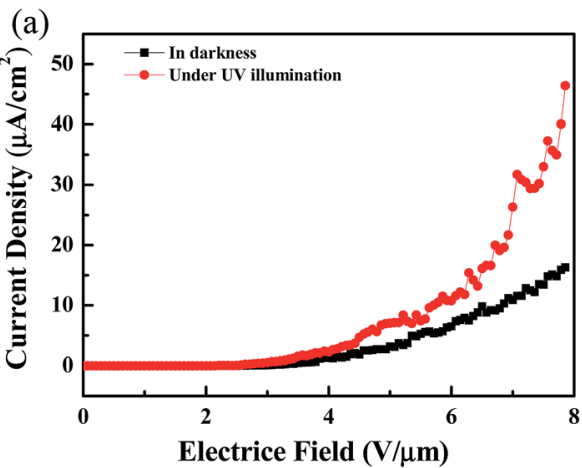

(b)

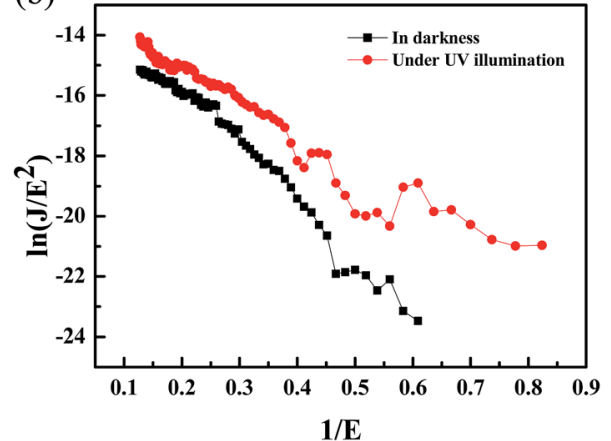

Fig. 4 (a) Field emission characteristics and (b) F-N plot of $\ln \left(J / E^{2}\right)$ versus 1/E of as-synthesized AZO nanosheets for the sample 3 .

Table 2 Presents the results of the field emission property analysis for the sample 3

\begin{tabular}{llll}
\hline Sample 3 & Turn-on $\left(E=\mathrm{V} \mathrm{\mu \textrm {m } ^ { - 1 } )}\right.$ & Slope & $\beta$ \\
\hline In darkness & 3.8 & 17.507 & 4760 \\
Under UV & 3.3 & 11.109 & 7501 \\
illumination & & &
\end{tabular}

$$
\text { Slope }=B \emptyset^{3 / 2} / \beta
$$

The field enhancement factor, or the work function, could be calculated with this equation. If the work function was $5.3 \mathrm{eV}$ for $\mathrm{ZnO}$, the field enhancement factors of the Al-doped $\mathrm{ZnO}$ nanosheets are approximately 4760 in the dark and 7501 under UV illumination, as shown in Fig. 4(b). According to the literature doping with aluminum greatly improved the field emission properties which mainly due to increase carrier concentration while aluminum doped in $\mathrm{ZnO}$ nanosheets by liberating more electrons. When an electric field was applied to the sample, the conductor band was bent to the Fermi level and the electrons tunneled to the vacuum level. Then, the carrier concentration increase with $\mathrm{Al}$ doped into the $\mathrm{ZnO}$ nanosheet, the more carriers exist in the conduction band. Moreover, as the Al-doped ZnO nanosheets was illuminated by UV light, a larger number of electron-hole pairs were generated and numerous electrons transferred to the conduction band, and the electric field was
Table 3 Field-emission characteristics of different nanostructure field emitters recently reported in the open literature

\begin{tabular}{lcll}
\hline Nanostructure & $\begin{array}{l}\text { Turn-on } \\
\left(\mathrm{V} \mu \mathrm{m}^{-1}\right)\end{array}$ & $\begin{array}{l}\text { Field enhancement } \\
\beta\left(\times 10^{3}\right)\end{array}$ & $\begin{array}{l}\text { Reference } \\
\text { no. }\end{array}$ \\
\hline ZnO nanorods & 9.2 & 0.87 & 26 \\
Tapered ZnO & 7.9 & 1 & 26 \\
$\begin{array}{l}\text { nanorods } \\
\text { ZnO nanowires }\end{array}$ & 5.1 & 1.7 & 27 \\
GaN nanowires & 8.4 & 0.47 & 28 \\
ZnO nanoneedles & 4.1 & 1.134 & 29 \\
ZnO nanocones & 6.2 & 2.252 & 30 \\
Tapered ZnS & 11.2 & 2.54 & 31 \\
nanostructures & & & \\
AZO nanosheets & 3.8 & 4.76 & In this \\
& & & work
\end{tabular}

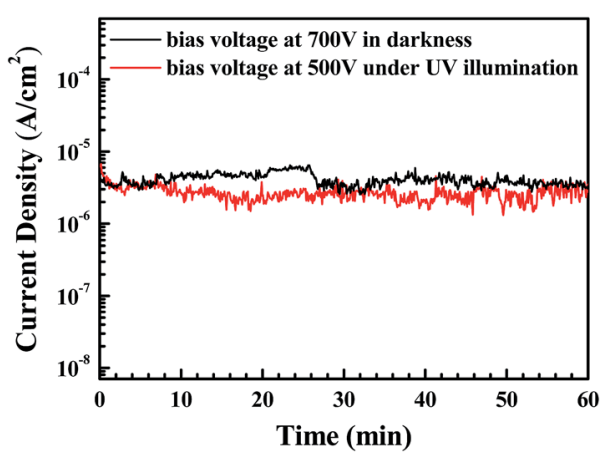

Fig. 5 Test of stability of emission current in the dark and under UV illumination.

established between the Al-doped $\mathrm{ZnO}$ nanosheet and the vacuum became larger, greater numbers of electrons moved toward the Al-doped $\mathrm{ZnO}$ nanosheet edges. These obtained values were considerably higher compared with the values recently reported by other groups, as reported in Table $3 .^{26-31}$ These results demonstrated the excellent long-term emission current stability of the Al-doped $\mathrm{ZnO}$ nanostructures. Fig. 5 illustrates the field emission device stability of the device in the dark and under UV. The current density was monitored for $3600 \mathrm{~s}$ with an initial emission current density of $10^{-6} \mathrm{~A} \mathrm{~cm}^{-2}$. The emission currents under UV varied because the electrons that were excited via UV illumination were not very stable. Thus, electrons were rapidly generated and recombined under UV illumination.

\section{Conclusions}

Using various growth temperatures, Al-doped $\mathrm{ZnO}$ nanosheets were synthesized on $\mathrm{ZnO} /$ glass substrate in aqueous solution. The field emission and physical properties of Al-doped ZnO nanosheets were then analyzed. The results of the analysis demonstrated that high temperatures improved the quality of the Al-doped $\mathrm{ZnO}$ nanosheets. Furthermore, the absence of other diffraction peaks in the samples indicated that the sample 
did not contain impurities and that the precursor was completely transformed into the $\mathrm{ZnO}$ phase. Compared with those of other samples, the PL intensity of the sample's UV emission peak (growth temperature at $60{ }^{\circ} \mathrm{C}$ ) was stronger. However, its broad, deep-level green emission band was weaker. This difference can be attributed to $\mathrm{Al}-\mathrm{Zn}$ ion interactions and increased growth temperature, which depleted oxygen ions and decreased oxygen interstitial concentration in the Al-doped $\mathrm{ZnO}$ nanosheets. The turn-on field of the Al-doped $\mathrm{ZnO}$ nanosheets was $3.8 \mathrm{~V} \mathrm{\mu m}^{-1}$ and their field enhancement factor $(\beta)$ was 4760 . UV illumination of the Al-doped $\mathrm{ZnO}$ nanosheets' decreased the turn-on electrical field from 3.8 to $3.3 \mathrm{~V} \mathrm{\mu m}^{-1}$ and increased the $\beta$ from 4760 to 7501 . The field emission performance of the nanosheets was better under UV illumination compared with in the dark.

\section{Acknowledgements}

This work was supported by Ministry of Science and Technology under contract numbers MOST 104-2221-150-042 and MOST 103-2221-E-150-034. This work was also supported by National Science Council of Taiwan under contract numbers NSC 1022221-E-150-046 and NSC 101-2221-E-150-043. The authors would like to thank the Common Laboratory for Micro/Nano Science and Technology, National Formosa University for providing the partial equipment for measurement. They would also like to thank the Center for Micro/Nano Science and Technology, National Cheng Kung University for the assistance in device characterization. The authors would also like to thank Mr Y. C. Chen for assistance in device fabrication.

\section{References}

1 W. A. Deheer, A. Chatelain and D. Ugarte, Science, 1995, 270, 1179.

2 M. Ahmad and J. Zhu, J. Mater. Chem., 2011, 21, 599.

3 Y. B. Guo, H. B. Liu, Y. J. Li, G. X. Li, Y. J. Zhao, Y. L. Song and Y. L. Li, J. Phys. Chem. C, 2011, 113, 12669.

4 N. de Jonge, M. Allioux, M. Doytcheva, M. Kaiser, K. B. K. Teo, R. G. Lacerda and W. I. Milne, Appl. Phys. Lett., 2004, 85, 1607.

5 Y. Saito, Y. Tsujimoto, A. Koshio and F. Kokai, Appl. Phys. Lett., 2007, 90, 213108.

6 X. H. Wang, L. Q. Huang, L. J. Niu, R. B. Li, D. H. Fan, F. B. Zhang, Z. W. Chan, X. Wang and Q. X. Gue, J. Alloys Compd., 2015, 622, 440.

7 X. Ge, K. Q. Hong, J. Zhang, L. Q. Liu and M. X. Xu, Mater. Lett., 2015, 139, 119.

8 A. Taabouche, A. Bouabellou, F. Kermiche, F. Hanini, Y. Bouachiba, A. Grid and T. Kerdjac, Mater. Sci. Semicond. Process., 2014, 28, 54.
9 Y. M. Huang, Q. L. Ma and B. G. Zhai, Mater. Chem. Phys., 2014, 147, 788.

10 N. A. Hambali, H. Yahaya, M. R. Mahmood, T. Terasako and A. M. Hashim, Nanoscale Res. Lett., 2014, 9, 609.

11 Y. C. Kong, D. P. Yu, B. Zhang, W. Fang and S. Q. Feng, Appl. Phys. Lett., 2001, 78, 407.

12 P. D. Yang, H. Q. Yan, S. Mao, R. Russo, J. Johnson, R. Saykally, N. Morris, J. Pham, R. R. He and H. J. Choi, Adv. Funct. Mater., 2002, 12, 323.

13 M. N. Jung, J. E. Koo, G. S. Kil, S. H. Park, W. J. Lee, D. C. Oh, H. J. Lee and J. H. Changa, J. Ceram. Process. Res., 2012, 13, 1. 14 G. M. Kumar and J. Park, J. Colloid Interface Sci., 2014, 430, 229.

15 Z. Zhang, J. Huang, H. He, S. Lin, H. Tang, H. Lu and Z. Ye, Solid-State Electron., 2009, 53, 578.

16 F. Ye, X. M. Cai, F. P. Dai, D. P. Zhang, P. Fan and L. J. Liu, Phys. Status Solidi A, 2011, 208, 1908.

17 K. Mahmood, R. Munir, B. S. Swain, G. S. Han, B. J. Kima and H. S. Jung, RSC Adv., 2014, 4, 9072.

18 C. L. Hsu, C. W. Su and T. J. Hsueh, RSC Adv., 2014, 4, 2980. 19 Y. C. Kong, D. P. Yu, B. Zhang, W. Fang and S. Q. Feng, Appl. Phys. Lett., 2001, 78, 407.

20 R. C. Wang, C. P. Liu, J. L. Huang and S. J. Chen, Appl. Phys. Lett., 2006, 88, 023111.

21 Q. Wan, T. H. Wang and J. C. Zhao, Appl. Phys. Lett., 2005, 87, 083105.

22 X. M. Fan, J. S. Lian, Z. X. Guo and H. J. Lu, Appl. Surf. Sci., 2005, 239, 176.

23 R. H. Fowler and L. W. Nordheim, Proc. R. Soc. London, Ser. A, 1928, 119, 173.

24 S. H. Jo, D. Banerjee and Z. F. Ren, Appl. Phys. Lett., 2004, 85, 1407.

25 X. D. Bai, E. G. Wang, P. X. Gao and Z. L. Wang, Nano Lett., 2003, 3, 1147.

26 N. Pan, H. Z. Xue, M. H. Yu, X. F. Cui, X. P. Wang, J. G. Hou, J. X. Hunag and S. Z. Deng, Nanotechnology, 2010, 21, 225707.

27 D. K. T. Ng, M. H. Hong, L. S. Tan, Y. W. Zhu and C. H. Sow, Nanotechnology, 2007, 18, 375707.

28 C. H. Chen, S. J. Chang, S. P. Chang, Y. C. Tsai, I. C. Chen, T. J. Hsueh and C. L. Hsu, Chem. Phys. Lett., 2010, 490, 176.

29 H. Y. Yang, S. P. Lau, S. F. Yu, L. Huang, M. Tanemura, J. Tanaka, T. Okita and H. H. Hag, Adv. Nan. Phys., 2005, 16, 1300.

30 Z. Zulkifli, S. Munisamy, M. Z. M. Yusop, G. Kalita and M. Tanemura, Jpn. J. Appl. Phys., 2013, 52, 11NJ07.

31 M. Hafeez, T. Y. Zhai, A. S. Bhatti, Y. Bando and D. Golberg, J. Phys. Chem. C, 2012, 116, 8297. 